\title{
Role of Endogenous Morphine in the Attenuation of Opiate Withdrawal Syndrome by N-acetylmuramyl-L-alanine- D-isoglutamine (MDP)
}

\author{
Inam D. Munjal, Dennis Schmidt, and Sydney Spector
}

Opiates, long considered the prototypical addictive drug, cause the phenomenon of tolerance and physical dependence following chronic administration. Although many factors promote the addictive state, our studies have focused on the role of endogenous morphine in modifying physical dependence. Mammalian tissues contain morphine and codeine and have the capacity to synthesize these alkaloids.

KEY WORDS: Endogenous morphine; Opiate withdrawal; $N$-acetylmuramyl-L-alanine-D-isoglutamate (MDP)

Muramyl dipeptide, N-acetylmuramyl-L-alanyl-D-isoglutamine (MDP) is the smallest subunit of the bacterial peptidoglycan that exerts various biological effects and has been shown to have a wide variety of immunomodulatory effects both in vitro and in vivo (Elloruz et al. 1974). MDP stimulates the production of interleukin-1 (II-1), tumor necrosis factor $\alpha$ (TNF- $\alpha$ ), and interleukin-6 (Il-6) (Vermeulen et al. 1987; Sanceau et al. 1990). MDP also induces numerous neuropharmacological alterations. It effects the unit discharge frequency of neurons in hypothalamus and hippocampus (Dougherty and Dafny 1990), it is somnogenic (Masek and Kadlecova

From the Department of Psychiatry (IDM; DS; SS) and the Department of Pharmacology (SS), Vanderbilt Medical School, Nashville, TN.

Address correspondence to: Dr. Sydney Spector, Department of Psychiatry, Vanderbilt Lniversity Medical Center, AA2232, Medical Center North, Nashville, TN 37232-2647.

Received April 12, 1995; revised August 2, 1995; accepted August 8, 1995.
The present report shows that $N$-acetylmuramyl-L-alanineD-isoglutamine (MDP), which elevates the endogenous opiate alkaloids in various brain regions and peripheral tissues, can attenuate the withdrawal syndrome of morphine-addicted rats. [Neuropsychopharmacology 15:99-103, 1996]

1987), it has analgesic activity (Masek 1986) and effects the electrophysiological responses of brain regions involved in various opioid activities (Dougherty and Dafny 1988). It also has been reported to modify the severity of naloxone-precipitated morphine withdrawal (Dougherty et al. 1987). The present study indicates that MDP also increases the levels of endogenous morphine and codeine that may be related to the attenuation of the withdrawal syndrome of opiate-addicted rats.

\section{MATERIALS AND METHODS}

Sprague-Dawley male rats (200-250 g) were used in these experiments. Rats were housed $0600-1800$ with lights on, food and water ad libitum, room temperature at $22^{\circ} \mathrm{C}$. Morphine dependence was induced by the subcutaneous injection of $5 \mathrm{mg} / \mathrm{kg}$ BID for 3 days. Opiate dependence was assessed by injecting the animals with $1 \mathrm{mg} / \mathrm{kg}$ naltrexone (IP) on the morning of the fourth day. The animals were placed in a transparent acrylic cage and monitored for 10 minutes after naltrexone ad- 
Table 1. Effect of Muramyl Dipeptide (3 mg/ $\mathrm{kg}$ IP) on Opiate Withdrawal Syndrome

\begin{tabular}{|c|c|c|c|c|}
\hline Treatment & $n^{a}$ & $\begin{array}{l}\text { Wet Dog } \\
\text { Shakes }\end{array}$ & $\begin{array}{c}\text { Teeth } \\
\text { Chattering }\end{array}$ & $\begin{array}{l}\text { Fecal } \\
\text { Boli }^{b}\end{array}$ \\
\hline Placebo + naltrexone & 6 & 0 & 0 & $7 \pm 2$ \\
\hline Morphine + naltrexone & 6 & $8 \pm 1^{c}$ & $8 \pm 2^{c}$ & Diarrhea \\
\hline Morphine + MDP + naltrexone & 6 & $3 \pm 1^{d}$ & $3 \pm 1^{d}$ & $4 \pm 1$ \\
\hline Placebo + MDP + naltrexone & 6 & 0 & 0 & $6 \pm 1$ \\
\hline
\end{tabular}

ministration. MDP test animals received MDP $(3 \mathrm{mg} /$ $\mathrm{kg}$ IP) 15 minutes prior to naltrexone administration. Withdrawal signs of wet dog shakes, teeth chattering, and fecal boli were assessed as signs of the withdrawal syndrome. Table 1 shows the protective effect of MDP on the withdrawal syndrome, similar to that reported by Dougherty et al. 1987.

Morphine and codeine were analyzed following HPLC and radioimmunoassay as described by Donnerer et al. (1987). Tissues were sonicated in $10 \mathrm{mM} \mathrm{HCl}$ (minimum volume, $3 \mathrm{ml}$ ). Concentrated $\mathrm{HCl}$ was added in a ratio of $6 \mathrm{ml}$ of acid to $10 \mathrm{ml}$ of tissue homogenate and then vortexed. Samples were then hydrolyzed in a water bath for 30 minutes at $95^{\circ} \mathrm{C}$, followed by cooling and centrifugation (10,000 $\times \mathrm{g}$ for 30 minutes). Samples were then applied to a C-18 Sep Pak cartridge that had been prewashed with $5 \mathrm{ml}$ methanol and $10 \mathrm{ml}$ distilled water. The cartridges were then washed with $7 \mathrm{ml}$ distilled water and eluted with $7 \mathrm{ml}$ of a solution contain- ing water $95.5 \%$, pyridine $0.8 \%$, glacil acetic acid $0.3 \%$, and n-propyl alcohol $0.3 \%$ (pH 5.2). The eluate was evaporated to dryness and resuspended in HPLC mobile phase (water $98.65 \%$, pyridine $0.8 \%$, glacil acetic acid $0.3 \%$, n-propyl alcohol $0.25 \%, \mathrm{pH} 5.2$ ) and placed over a Lichosorb RP-18, $10-\mu \mathrm{M}$ column $(250 \mathrm{~mm})$. One$\mathrm{ml}$ fractions were collected, corresponding to fractions where standards elute. The fractions were evaporated to dryness and resuspended in $250 \mu$ l of phosphate buffered saline ( $\mathrm{pH}$ 7.4). The alkaloids were analyzed by radioimmunoassay.

\section{RESULTS}

We have previously shown that MDP elevated morphine and codeine levels in brain and peripheral organs in mice (Horak et al. 1993). Because exogenously ad-
Figure 1. Endogenous morphine levels in different brain regions of rats $(n=6)$ treated with MDP $(3 \mathrm{mg} / \mathrm{kg}$ IP). Animals were sacrificed 30, 60 and 90 minutes after MDP administration. Data are presented as mean \pm SEM. ${ }^{*} p<.005$ versus control. Bars: 0 minutes, $30 \mathrm{~min}$ utes, 60 minutes, and 90 minutes respectively.

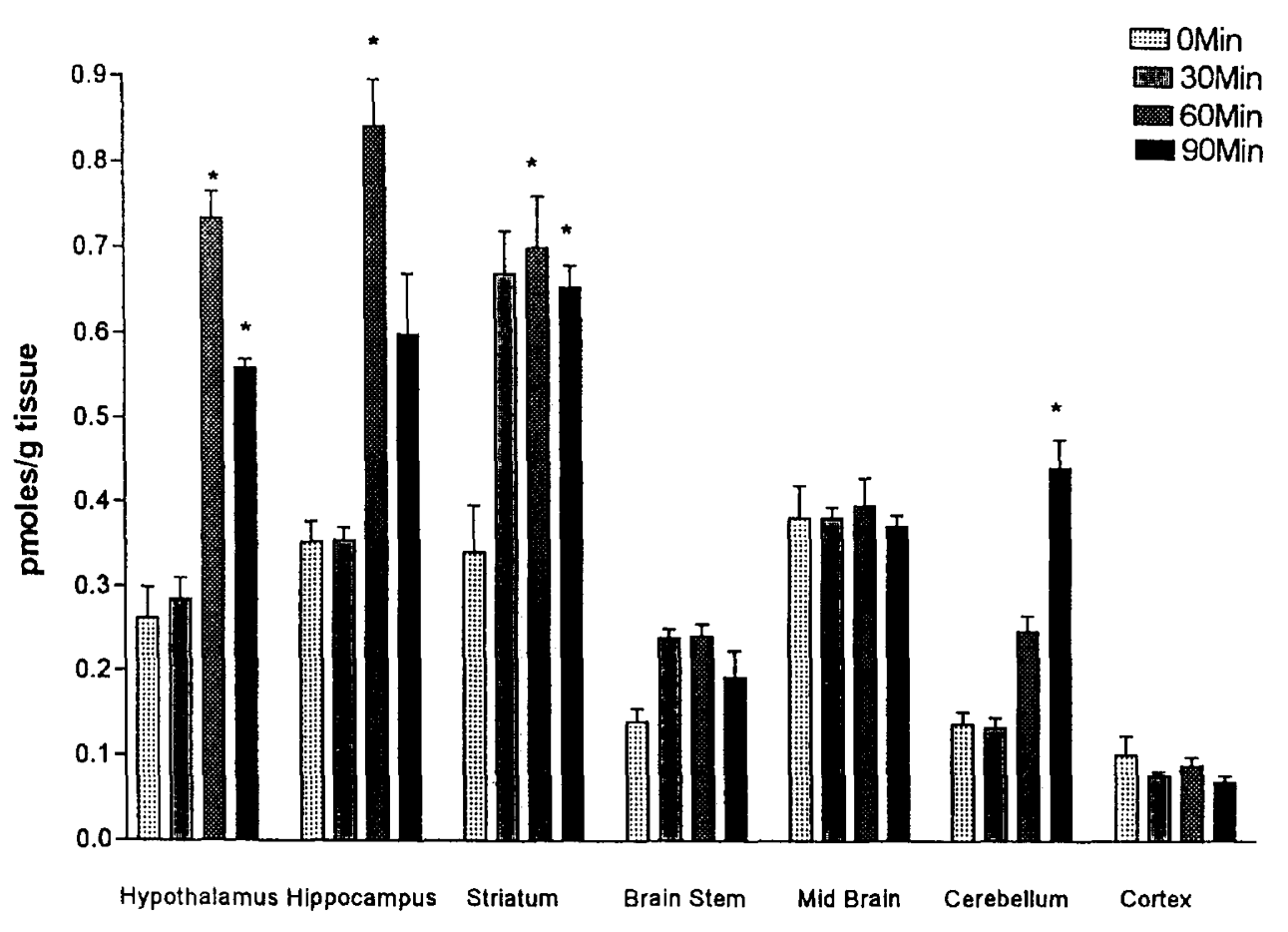




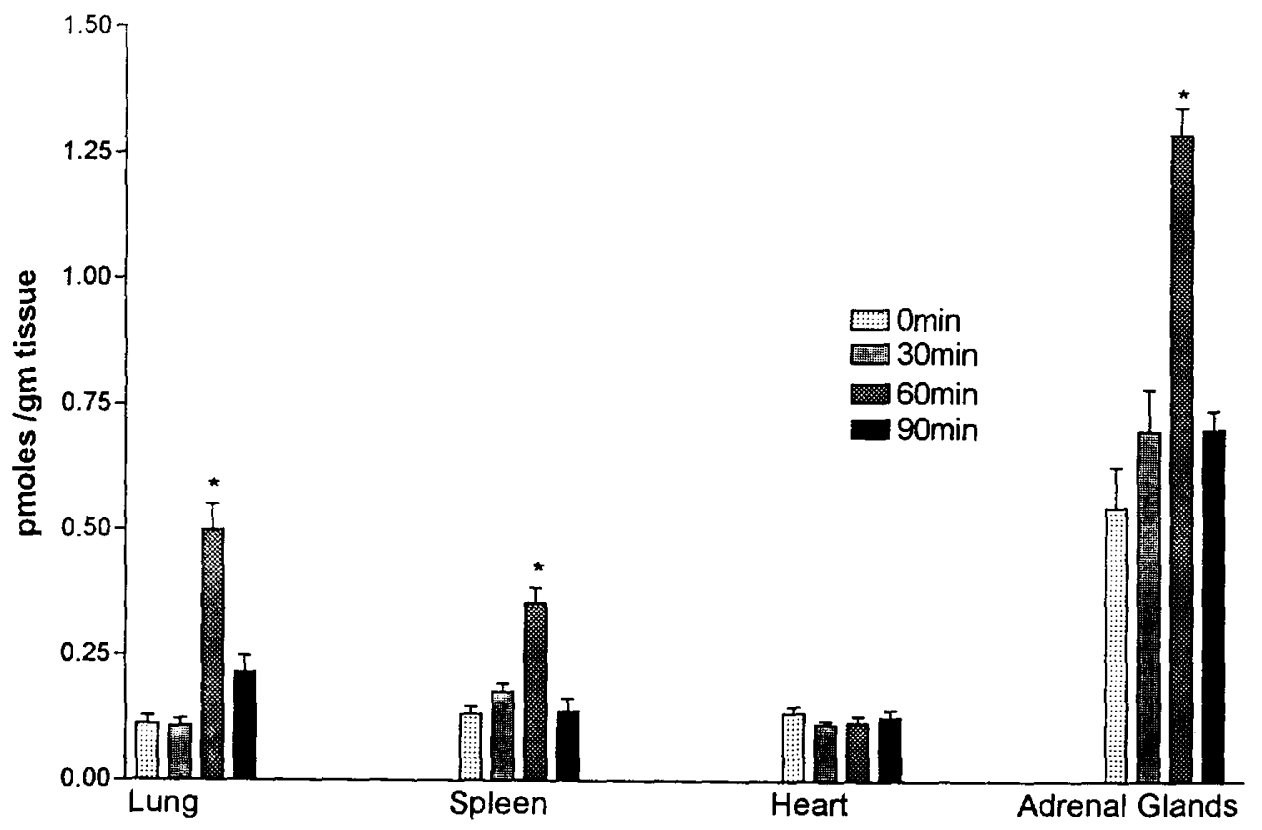

Figure 2. Endogenous morphine levels in lung, spleen, heart, and adrenal glands of rats $(n=6)$ treated with MDP ( $3 \mathrm{mg} / \mathrm{kg} \mathrm{IP}$ ). Animals were sacrificed 30, 60 and 90 min. after MDP administration. Data are presented as mean \pm SEM. ${ }^{*} p<.005$ versus control. Bars: 0 minutes, 30 minutes, 60 minutes, and 90 minutes respectively.

ministered morphine interferes with the determination of endogenous morphine, we were required to determine the effects of MDP on endogenous morphine (Figures 1 and 2) and codeine (Figures 3 and 4) in various brain regions and peripheral organs of morphine-naive rats. The levels of morphine were increased in the hypothalamus, hippocampus, striatum, cortex, and cerebellum. MDP also increased morphine levels in lung and spleen. Codeine, the immediate precursor of morphine, also increased in the same brain regions as morphine, with the exception of the cortex. The same pattern is seen in peripheral tissues, where MDP elevated codeine levels in lung and spleen.

\section{DISCUSSION}

The concomitant increase in morphine levels and the attenuation of morphine-dependent withdrawal signs by MDP suggest that the endogenous opiate alkaloids may be involved in this effect. We postulate that the elevated endogenous morphine may substitute for the exogenous morphine in a manner similar to that of methadone. The question arises as to whether the levels of the endogenous morphine are sufficient to compete with naltrexone at relevant receptor sites. Our tissue analysis of morphine is from comparatively large heterogeneous brain regions, and it is possible that the morphine levels

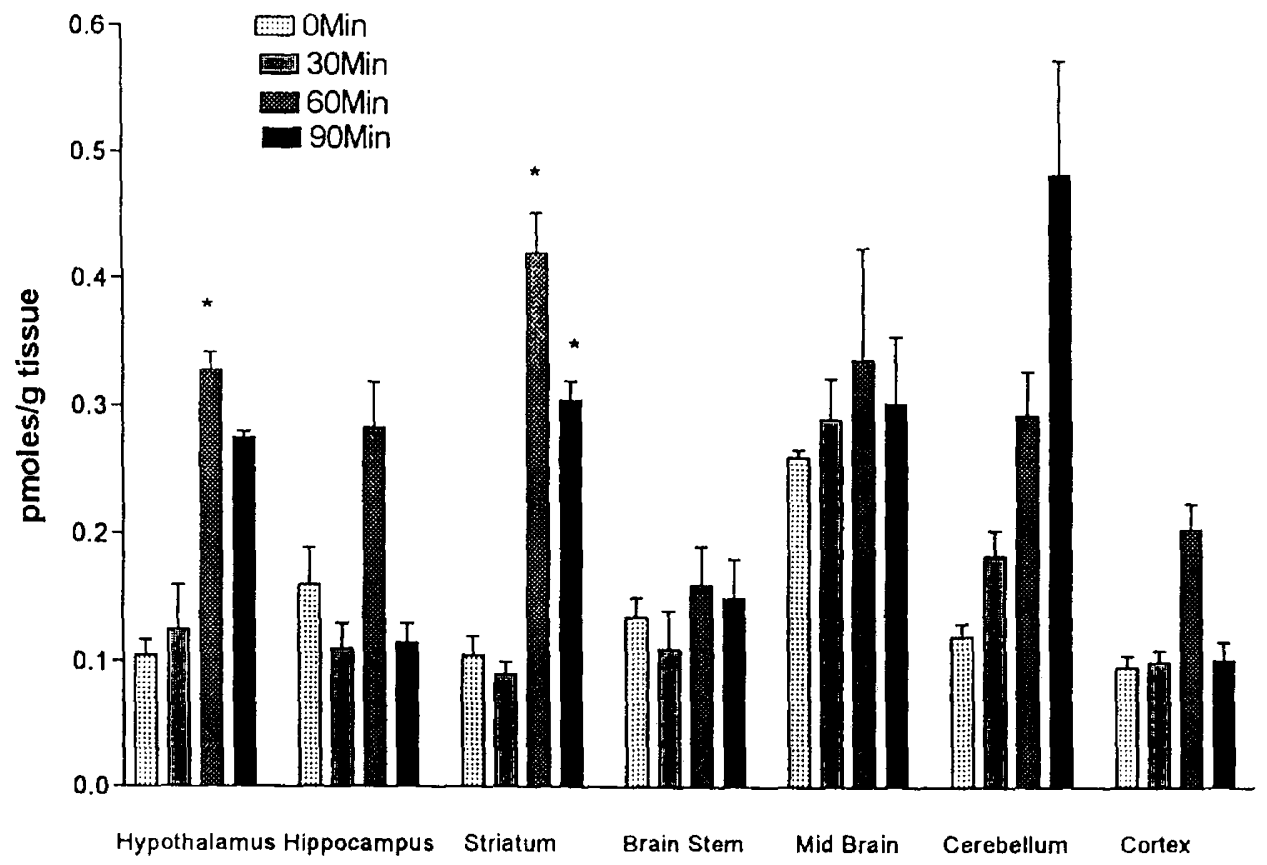

Figure 3. Endogenous codeine levels in different brain regions of rats $(n=6)$ treated with MDP ( $3 \mathrm{mg} / \mathrm{kg}$ IP). Animals were sacrificed 30,60 and 90 minutes after MDP administration. Data are presented as mean \pm SEM. ${ }^{*} p<.005$ versus control. Bars: 0 minutes, 30 minutes, 60 minutes, and 90 minutes respectively. 
Figure 4. Endogenous codeine levels in lung, spleen, heart, and adrenal glands of rats $(n=6)$ treated with MDP ( $3 \mathrm{mg} / \mathrm{kg}$ IP). Animals were sacrificed 30,60 , and 90 minutes after MDP administration. Data are presented as mean \pm SEM. ${ }^{*} p<.005$ versus control. Bars: 0 minutes, 30 minutes, 60 minutes, and 90 minutes respectively.

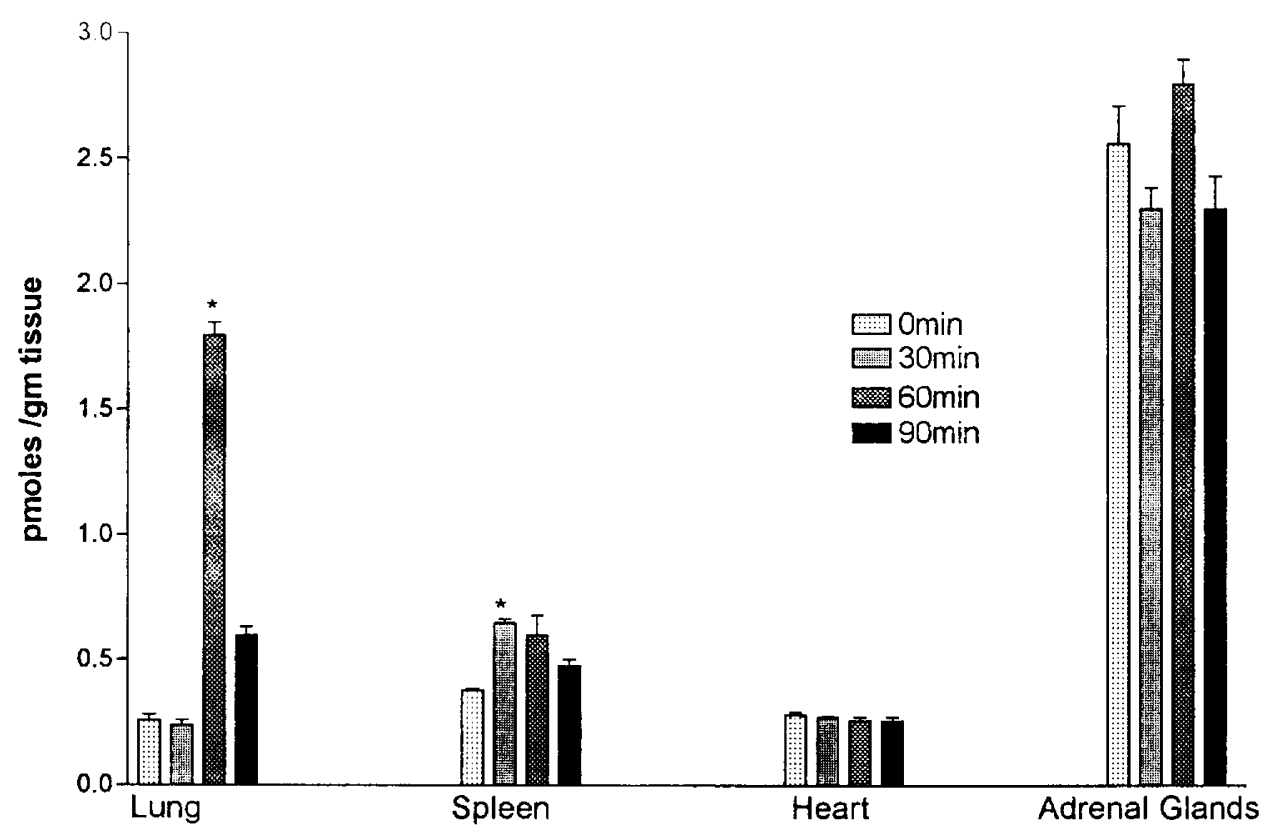

are much greater at critical sites in the brain microenvironment. It has been shown that chronic morphine treatment upregulates the CAMP system with the consequence of an increased excitability of specific neurons in the central nervous system (CNS) (Nestler et al. 1989). It has also been demonstrated that chronic morphine enhances protein phosphorylation of specific substrates for cAMP-dependent protein kinase, which may play a role in the development and expression of morphine addiction (Guitart and Nestler 1989). The elevated endogenous morphine may maintain the activity of cAMPdependent protein kinase and thus attenuate the development of the behavioral signs of physical dependence.

Another explanation for the attenuation of naltrexone-precipitated withdrawal is that the brain contains phenolsulfa transferase activity (Foldes and Meek 1974) and the enzyme may produce morphine-3-sulfate and/ or morphine-6-sulfate within the brain. In a previous report (Donnerer et al. 1987) we have demonstrated that the sulfated form of morphine exists in the CNS. Both these morphine sulfates have been reported to be more potent analgesics than morphine (Brown et al. 1985), and it is possible that they mediate some of the effects of the endogenous morphine.

Our results suggest a potentially important role for the endogenous morphine or codeine in modifying the effects of physical dependence from exogenous opiates (morphine or heroin) and the clinical potential of drugs that are capable of elevating the endogenous morphine content.

\section{REFERENCES}

Brown CE, Roerig SC, Burger VT, Coty RB Jr, Fujimoto JM (1985): Analgesic potencies of morphine 3 and 6-sulfates after intraventricular administration in mice: Relationship to structural characteristics defined by mass spectrometry and nuclear magnetic resonance. J Pharmaceut Sci 74:821-824

Donnerer J, Cardinale G, Coffey J, Lisek CA, Jardine I, Spector $S$ (1987): Chemical characterization and regulation of endogenous morphine and codeine in the rat. J Pharmacol Exp Ther 242:583-587

Dougherty PM, Dafny M (1988): Neuroimmune intercommunications central opioids and the immune response to bacterial endotoxin. J Neurosci Res 19:140-148

Dougherty PM, Dafny M (1990): Muramyl dipeptide a macrophage cytokine alters neuronal activity in hypothalamus but not in the dorsal raphe periaquaductal grey of rats. J Neuroimmunol 28:201-208

Dougherty PM, Drath DB, Dafny M (1987): Evidence of an immune system to brain communication axis that affects central opioid function: Muramyl peptides attenuates opiate withdrawal. Eur J Pharmacol 141:253-260

Ellouz FS, Adam A, Crobaru R, Lederer E (1974): Minimal structural requirements for adjuvant activity of bacterial peptidoglycan derivatives. Biochem Biophys Res Comm 59:1317-1325

Foldes A, Meek JL (1974): Occurrence and localization of brain phenolsulfatransferase. J Neurochem 23:303-307

Guitart X, Nestler EJ (1989): Identification of morphine and cyclic AMP regulated phosphoproteins (MAPPS) in the locus coeruleus and other regions of rat brain. Regulation by acute and chronic morphine. J Neurosci 9:4371-4387

Horak P, Haberman F, Spector S (1993): Endogenous morphine and codeine in mice. Effect of muramyl dipeptide. Life Sci 52:255-260

Masek K (1986): Immunopharmacology of muramyl dipeptide. Fed Proc 45:2549

Masek K, Kadlecova (1987): Muramyl peptides, serotonergic system and sleep. Ann NY Acad Sci 496:517-521 
Nestler EJ, Terwilliger R, Erdos JJ, Duman RS, Tallman JF (1989): Regulation of $G$ proteins by chronic morphine in the rat locus coeruleus. Brain Res 476:230-239

Sanceau J, Falcoff R, Beranger F, Carter DB, Wietzerbim J (1990): Secretion of interleukin-6 (Il-6) by human mono- cytes stimulated by muramyl dipeptide and tumor necrosis factor alpha. J Immunol 69:52-56

Vermeulen MW, David JR, and Remold HG (1987): Differential mRNA responses in human macrophages activated by interferon $\delta$ and muramyl dipeptide. J Immunol 139:7-9 